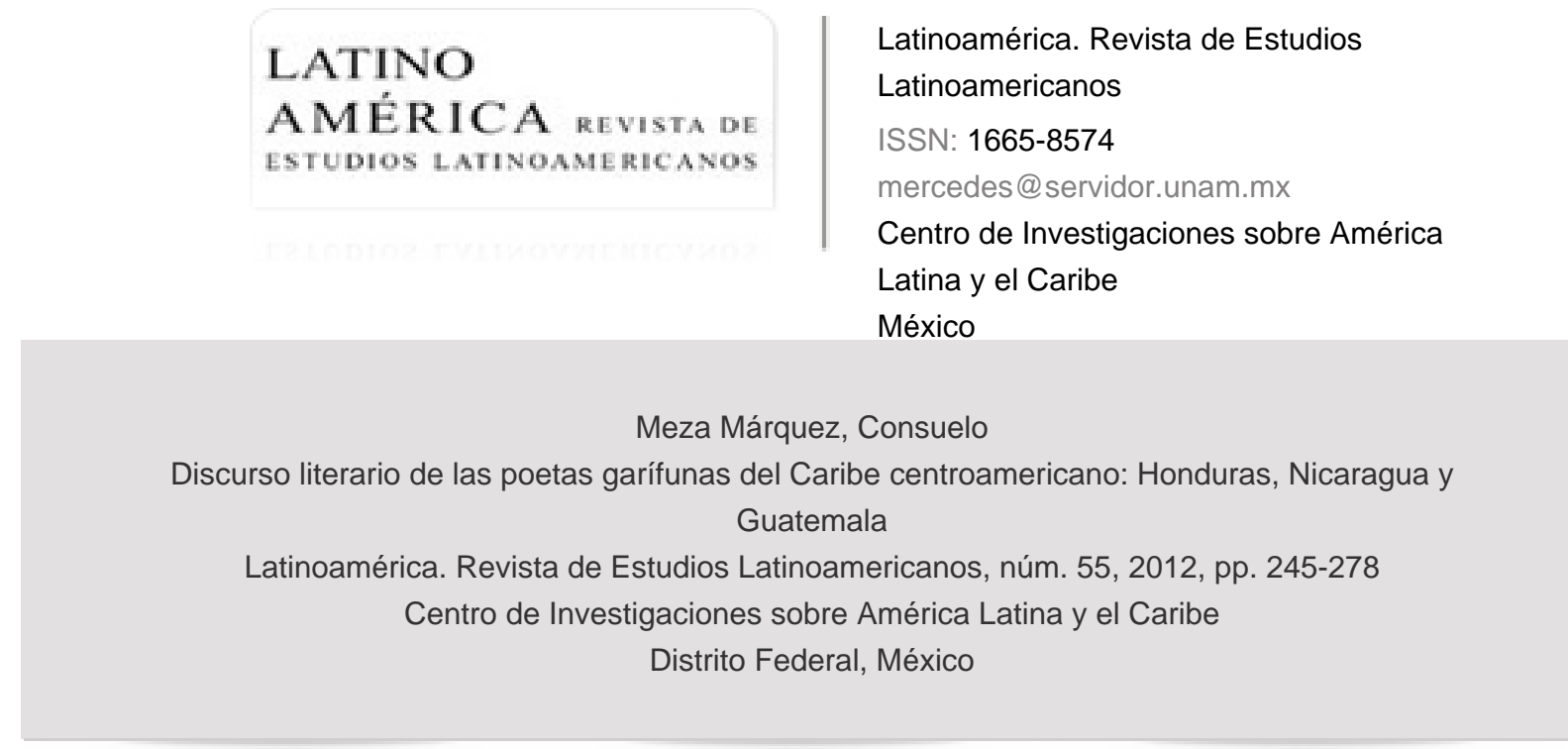

Disponible en: http://www.redalyc.org/articulo.oa?id=64024698010

Cómo citar el artículo

- Número completo

- Más información del artículo

- Página de la revista en redalyc.org

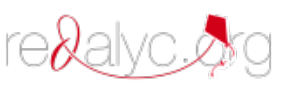

Sistema de Información Científica

Red de Revistas Científicas de América Latina, el Caribe, España y Portugal Proyecto académico sin fines de lucro, desarrollado bajo la iniciativa de acceso abierto 


\title{
Discurso literario de las poetas garífunas del Caribe centroamericano: Honduras, Nicaragua y Guatemala
}

\author{
Consuelo Meza Márquez*
}

Resumen: El ensayo muestra la obra poética de las escritoras garífunas del Caribe centroamericano como un discurso en el que pueden observarse los procesos de construcción de la identidad como garífunas y como mujeres. Es un movimiento contradiscursivo, que funciona como suplemento de la historia, la memoria y las tradiciones culturales. En ese proceso, la labor de las mujeres como transmisoras de cultura es fundamental en la vida cotidiana, en el devenir histórico y en el proceso de representación en la literatura. Es un discurso afrocéntrico que construye un movimiento más allá de las fronteras de los diferentes países y recupera símbolos, imágenes, sueños e ideales que permiten la permanencia de la etnia garífuna.

Palabras clave: Poesía, Identidad, Mujeres, Garifunas, Caribe, Centroamérica.

ABSTRACT: The paper shows the poetic works of Garifuna women writers from Caribbean Central America. Their discourse shows the construction of an identity as garifuna and as women. It is an underground movement that works as a supplement to history, memory, and cultural traditions. In this process, the work of women as transmitters of culture is central to daily life, throughout history, and in the practice of representation in literature. This central-African discourse is creating a movement beyond the borders of the different countries with garifuna population, and is recovering symbols, images, dreams, and ideals that allow their permanency of the gariffuna ethnicity.

Key words: Poetry, Identity, Women, Garífuna, Caribbean, Central America.

\footnotetext{
"Universidad Autónoma de Aguascalientes (cmeza@correo.uaa.mx).
} 


\section{El día que yo muera, que me entierren vestida en mi Gudú y me amarren mi Musúwe en mi cabeza.}

Cheryl Noralez

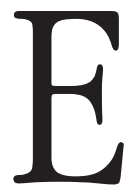

1 ensayo tiene como objetivo realizar un breve recorrido de la obra poética de las escritoras garífunas centroamericanas de los países de habla hispana como son Guatemala, Honduras y Nicaragua. Se pretende identificar las temáticas y marcas en su escritura, sus preocupaciones y anhelos. La primera parte del análisis realiza una descripción del contexto histórico y actual en el que vive la población garífuna en los distintos países. Es un apartado relativamente extenso; se consideró necesario porque con frecuencia se le confunde con la población creole de origen afroantillano que, como fuerza de trabajo barata, emigró a Centroamérica para la construcción de las grandes obras de infraestructura como los ferrocarriles y el Canal de Panamá, y la explotación de la agricultura comercial de exportación a finales del siglo XIX. La asimilación se debe, en parte por el color de la piel y la ascendencia africana, y también porque como minoría étnica han adoptado rasgos culturales de los creoles. Sin embargo, algo que marca la diferencia entre los creoles y los garinagu es que estos últimos no llevan en su memoria las marcas de la esclavitud sino de la rebelión y la lucha frente a la misma. Generalmente en los diferentes tipos de estudios sobre afrodescendientes del Caribe centroamericano, se incluye a los garífunas en esta categoría, sin tomar en cuenta los diferentes periodos y condiciones históricas en que ambos grupos étnicos llegaron a Centroamérica.

La parte medular del trabajo se refiere al discurso de las poetas garífunas que reafirma su memoria e identidad exaltando los rasgos culturales de la etnia, expresando el deseo del reconocimiento como ciudadanos en países que los discriminan por el color de la piel. La selección de las autoras obedece a que, hasta el presente, son las únicas que se han podido identificar por la crítica literaria feminista, son mujeres que han logrado romper el cerco de la invisibili- 
dad. No se incluyen escritoras beliceñas como Jessie Núñez Castillo, Zoila Ellis Browne y Adele Ramos Daly porque las preocupaciones y temáticas se encuentran muy cercanas a las de las escritoras creoles. Por ello el ensayo se concentra en las escritoras Xiomara Cacho Caballero de Honduras, Isabel Estrada Colindres de Nicaragua, Lecian Haye Francis y Nora Murillo de Guatemala. El presente análisis surge de una investigación pionera que no pretende ser exhaustiva, busca despertar el interés y ofrecer pistas de búsqueda, desde nuevas miradas, para futuros estudios.

\section{LOS GARífunAS EN CENTROAMÉRICA}

La etnia garífuna nació de la mezcla entre negros fugitivos e indios caribes en la isla de San Vicente, en las Pequeñas Antillas. La historia relata que en 1635, dos barcos españoles dedicados al tráfico de esclavos, del ahora territorio de Nigeria, se hundieron en la costa de San Vicente. Algunas fuentes narran, incluso, que fueron los mismos esclavos los que provocaron el hundimiento. Los que sobrevivieron encontraron refugio en los caseríos de los indios caribes que ahí vivían. Los dos grupos étnicos se mezclaron y dieron origen a la cultura garífuna. En un sentido estricto el gentilicio "garinagu" se refiere a las personas y "garífuna" a la lengua y la cultura. ${ }^{1}$

Desde la isla de San Vicente, los caribes atacaban las posiciones europeas en otros territorios y daban refugio a esclavos africanos que huían de las plantaciones de las islas vecinas o procedentes de naufragios y rebeliones de barcos negreros. En la segunda mitad del siglo xvi, los franceses iniciaron la ocupación de San Vicente, pero la resistencia de caribes y negros los obligó a firmar un tratado que cedía la isla a los insurrectos a cambio de que terminaran sus ataques. En el siglo xviII se intensifica una disputa entre franceses e ingleses por el control de la isla con la finalidad de establecer una economía de plantación. Al

1 Garifuna People. En http://www.southernbelize.com/hist_garifuna.html. 
mismo tiempo, se consolida la partición del territorio en un occidente indígena y un oriente negro. ${ }^{2}$

El grupo étnico que permaneció en la región oriental fue el de los garífunas, a quienes los colonialistas ingleses denominaban "caribes negros" para distinguirlos de los "caribes rojos" o "caribes amarillos" a los que consideraban indios puros. Esta etnia de africanos y afrodescendientes había adoptado la lengua y los elementos culturales de los indios caribes. Los ancestros africanos de los garífunas eran negros cimarrones y las raíces indoamericanas de los caribes y arawacos (tres siglos antes de la conquista europea de América, los caribes iniciaron un desplazamiento desde la costa septentrional sudamericana y la cuenca del Orinoco hasta las Antillas pobladas por arawacos). En 1763, por el Tratado de París, San Vicente pasó a manos de los británicos y la presión sobre los garífunas se agudizó, de tal manera que revolucionarios franceses, a principios de la década de 1790, convirtieron a los garífunas en sus aliados contra los ingleses. Esto dio origen al conflicto que se conoció como las Guerras Caribes, que terminó con la derrota de caribes y franceses y la deportación de los negros caribes a la isla de Balliceaux en las Granadinas. ${ }^{3}$

En marzo de 1797, los 2248 supervivientes de las guerras y epidemias fueron deportados nuevamente a la isla de Roatán (en las islas de la Bahía frente a la actual Honduras). El 12 de abril de 1797 se consigna la llegada de 2026 garífunas a Roatán; 222 murieron en el trayecto. De la isla, los garífunas se trasladaron a la ciudad de Trujillo y desde ahí emigraron a otros lugares del litoral atlántico centroamericano conformando una línea de pueblos, ciudades y barrios, casi siempre junto al mar, que corre del sur de Belice al norte de Nicaragua, pasando por Guatemala y Honduras. En estos lugares establecieron, durante el siglo xIx, comunidades que vivían de la agricultura, yuca y plátano, de la pesca y del trabajo asalariado en plantaciones bananeras, compañías marítimas y puertos. ${ }^{4}$

2 Gabriel Izard, "Garífuna y seminole negros: mestizajes afroindígenas en Centro y Norteamérica", en Elizabeth Cunin [coord.], Mestizaje, diferencia y nación. Lo "negro" en América Central y el Caribe, México, INAH, 2010, pp. 197-205.

3 Ibid., pp. 205 y 206.

4 Ibid., pp. 206 y 207. 
La cultura garífuna es una amalgama de elementos caribes, africanos, afroamericanos, europeos, y centroamericanos que han evolucionado e integrado nuevas influencias para formar una cultura compleja en la que destacan la lengua, la religión, la alimentación, la música y la danza. Los garífunas son poseedores de una cultura que incorpora las tradiciones africanas de la música, danza, ritos y ceremonias religiosas; las formas de subsistencia como son las técnicas de cultivo de la yuca, el tipo de alimentación, caza y pesca provienen de los indios caribes; y una lengua de influencia francesa y arawaca. Los números, por ejemplo, son los mismos que en francés y algunas palabras y expresiones resultan de la fusión del francés y arawaco. ${ }^{5}$

Según el investigador Gabriel Izard, la lengua garífuna es amerindia (caribearawaco) con aportación léxica europea (francesa, inglesa, española), la fonética de influencia africana y la propia evolución de la lengua. ${ }^{6}$ Una de las particularidades de la lengua es que las mujeres utilizan ciertas palabras y los varones otras para referirse a lo mismo. Las palabras utilizadas por los hombres provienen de los indios caribes y las usadas por las mujeres proceden de los arawacos. ${ }^{7}$

La religión está centrada en los ancestros, compaginan sus creencias con las del catolicismo, cuya influencia se remonta a la conversión por parte de los misioneros franceses en San Vicente. Así, la mayoría de los garífunas son católicos, con excepción de los que se trasladaron a Belice que reciben la influencia de las creencias anglicanas, por su pertenencia al imperio británico hasta 1981.

La base de la alimentación se encuentra en la yuca, el plátano, el pescado y el coco. De hecho, el gentilicio garinagu se deriva de calínago o comedores de yuca. El budut (plátano molido que se acompaña con pescado y leche de coco) y el casabe (pan de yuca) son sus platillos básicos.

Respecto a la música y la danza, los tambores constituyen el elemento principal. Las canciones y danzas dugu, frecuentemente realizadas por mujeres, forman parte del ritual religioso de los ancestros. Esta celebración es presidida por

5 Garifuna. En http://www.clas.ufl.edu/users/afburns/afrotrop/Garifuna.htm.

6 Izard, op. cit., p. 207.

7 Víctor Virgilio López García, El papel de la mujer en la cultura garífuna, San Pedro Sula, Impresos Rápidos Ariel, 2007, p. 43. 
un sacerdote-curandero garífuna. La punta es un ritmo secular que se baila en velorios, fiestas y otros actos sociales, las letras de estas canciones son generalmente compuestas por mujeres; el wanaragua, de origen afroantillano, se baila en las fiestas navideñas; el punta rock es un ritmo popular actual que surge de la punta con electrificación mezclada con ritmos afrocaribeños como calypso y soca. ${ }^{8}$

Respecto a la división del trabajo, las mujeres se dedican al cultivo de la yuca y los hombres a la caza y a la pesca. Los garífunas son reconocidos por sus habilidades marítimas. Los pescadores salen al mar antes de que amanezca, mientras que las mujeres cultivan la tierra y preparan los alimentos, que consisten en pescado fresco y casabe, plátano, piña y coco. Los niños realizan las labores de la casa, lavan la ropa, limpian el pescado y hacen los mandados; los abuelos enseñan a los nietos las habilidades requeridas para la subsistencia y para la reproducción de la cultura. Este modo de vida y el aislamiento en que se encuentran ha sido un elemento que ha favorecido la permanencia de la cultura. ${ }^{9}$

La cultura garífuna es matrilocal y matrilineal. Con el matrimonio, el hombre pasa a formar parte de la familia de la esposa y está obligado a edificar su casa en la propiedad de los padres de ella. Lo anterior permite el establecimiento de lazos de parentesco del lado de la mujer. ${ }^{10}$ Las mujeres son el centro del hogar y las encargadas de la subsistencia biológica, de la educación de los hijos e hijas y de la reproducción y transmisión de las tradiciones. Son poderosas y toman decisiones al interior del hogar y la comunidad, ya que es muy frecuente que los hombres estén fuera. Sin embargo, esto no significa que sean independientes, porque dependen de los ingresos de los esposos para sostener a la familia. El acceso de las mujeres al trabajo asalariado se encuentra limitado al trabajo doméstico y a la venta de productos hechos en casa, lo que no proporciona un ingreso suficiente. La familia garífuna dependía de la agricultura para la obten-

8 Izard, op. cit., pp. 207-209.

9 Tangled history of garifuna people. En http://www.hostalgarifuna.net/index.php?option= com_content \&view=article\&\&id=65\%3Atangled-history-of-garifuna-people rsidRPr="0022rn/ unotaalpie" $/>$.

${ }^{10}$ López García, op. cit., p. 87. 
ción de sus ingresos. Sin embargo, el acceso a la tierra de vocación agrícola se vio limitado por la entrada de las compañías fruteras, principalmente plátano durante el siglo xx. Se permitió el ingreso a la agricultura comercial porque suponía la generación de ingresos para las comunidades pero, conforme esta actividad fue declinando, la tierra fue vendida a los agricultores mestizos. Los garífunas se vieron obligados a emigrar en la búsqueda de empleo con compañías extranjeras dedicadas a la explotación de madera y chicle, como pescadores o como obreros que han migrado a las capitales centroamericanas y a Estados Unidos. Otra fuente de empleo ha sido la Marina Mercante. A las mujeres no les es permitido desempeñarse en estas actividades, pese a ello, se han visto obligadas a emigrar a las ciudades, incluso a Estados Unidos, en busca de trabajo, las más de las veces como empleadas domésticas o en la industria textil.

En esta organización matrilocal, en el pasado, los hogares estaban integrados por tres generaciones de mujeres: la abuela, la madre y las hijas e hijos. Es frecuente encontrar, a partir de la década de los sesenta, hogares donde permanecen las abuelas y los niños. Son ellas las encargadas ahora de la crianza y dependen en buena parte de los envíos monetarios que realizan los miembros de la familia que están fuera. Son abuelas y abuelos los que educan a los niños y cuando éstos crecen también emigran. Se calcula que 50\% de los varones han estado fuera de la comunidad en algún momento de sus vidas, y con la creciente emigración de las mujeres, las comunidades garífunas están perdiendo una generación de adultos en edad productiva. ${ }^{11}$

Los miembros de la etnia radican en Centroamérica, Estados Unidos y Yurumein (San Vicente y las Granadinas). Es difícil hacer un conteo de la población debido al proceso migratorio y porque solamente Belice los contabiliza como un grupo étnico específico, pero se calcula su existencia entre 200 y 500 mil garífunas, y alrededor de 100 mil en Estados Unidos. ${ }^{12}$

${ }^{11}$ Garifuna. En http://www.everyculture.com/wc/Afghanistan-to-Bosnia-Herzegovin...

12 Ibid. 
Una de las preocupaciones es la reactivación de la cultura y su identidad como garífunas más allá de las fronteras de los países en que viven. Comparten una historia común y celebraciones, se encuentran unidos por blogs de los distintos países con enlaces a los otros. En la actualidad existe la Garifuna Heritage Foundation, con sede en San Vicente, que en marzo de 2012 realizó una Conferencia Internacional con el tema "Viviendo la herencia y cultura garífuna después de 215 años. Fortaleciendo vínculos, creando redes y recuperando espacios ancestrales". La fundación es dirigida por la escritora garífuna-beliceña Zoila Ellis Browne.

Esa revitalización de la cultura va más allá de la preocupación por la conservación de su lengua o del reconocimiento de su memoria e historia común, incluye la construcción de condiciones que permitan la reproducción social del grupo a través, por ejemplo, de la educación. El investigador Gabriel Izard señala:

Los garífunas están preocupados por el futuro de su cultura, ya que la educación en las escuelas no es en su lengua, no hay prensa y una televisión garífuna, y viven en países donde a pesar de la diversidad cultural hay la hegemonía de un grupo étnico o lingüístico determinado (el creole, formado por los descendientes de los esclavos africanos traídos por los ingleses y los descendientes del mestizaje de los primeros con los segundos, en Belice; el mestizaje hispano-parlante en los otros países de Centroamérica). ${ }^{13}$

\section{LA LITERATURA DE LAS POETAS GARÍFUNAS CENTROAMERICANAS}

La obra poética de las escritoras garífunas del Caribe centroamericano representa un discurso en el que pueden observarse los procesos de construcción de la identidad como integrantes de la etnia garífuna y como mujeres. Es un movimiento que funciona como suplemento de la memoria y que mantiene presentes, en el imaginario, las tradiciones culturales. En ese proceso, la labor de las mujeres como transmisoras de cultura es fundamental en la vida cotidiana, en

13 Izard, op. cit., p. 211. 
el devenir histórico y en el proceso de representación en la literatura. Es un discurso que trasciende las fronteras de los diferentes países en los que habitan miembros de la etnia. No es un discurso aislado sino que se une a otras voces de afrodescendientes que desde una visión afrocéntrica expresan la vivencia de un cuerpo marcado por la etnia en condiciones de minoría, discriminación y explotación. En este sentido el costarricense Quince Duncan señala como preocupación, la búsqueda de la identidad de los sujetos como afrodescendientes en países de tradición hispánica con población indígena, que incorpora la reivindicación de la memoria histórica africana y que se expresa en inglés criollo costeño o creole como producto de los movimientos de la diáspora negra en el trayecto de África, las islas antillanas (angloparlantes) y Centroamérica. ${ }^{14}$

\section{Xiomara Cacho Caballero: Honduras}

En Honduras existe un movimiento importante de la población garífuna que reivindica su memoria, su historia, su cultura, su idioma, sus héroes y personajes, sus tradiciones y todo aquello que construye su identidad. Denuncia la discriminación de la que son objeto los miembros de esta etnia en los diferentes países ${ }^{15}$ y su exclusión de los discursos nacionales.

En el caso de Honduras, los garífunas o "morenos"-categoría étnica utilizada para distinguirse de los negros creoles- se consideran a sí mismos como nacionales hondureños. Sixto Cacho escribió el artículo periodístico "Por la Raza Morena y la Protección de todos mis Compatriotas" en el que afirma "Los morenos que habitan en Honduras son también sus hijos legítimos. . . Yo puedo demostrar a quien lo solicite que la raza caribe que puebla la costa Norte de Honduras, desciende de los habitantes que encontró Cristobal Colón, en las islas y tierra firme,

${ }^{14}$ Quince Duncan, "El Afrorrealismo. Una dimensión nueva de la literatura latinoamericana", en Istmo. Revista Virtual de Estudios Literarios y Culturales Centroamericanos, núm. 10, enerojunio de 2005. En http://collaborations.denison.edu/istmo/n10/articulos/afrorealismo.html (fecha de consulta: 8 de octubre, 2009).

15 Véase http://www.garinet.com. 
cuando el descubrimiento de América." ${ }^{16}$ El reclamo es en el sentido de su asimilación y discriminación frente a la población afroantillana, creole, que llegó a Honduras para trabajar en las compañías norteamericanas del puerto de Tela y la Truxillo Railroad Company. La asimilación es en el sentido en que se les identificó como negros con todas las connotaciones y discriminación que esto representaba. Las compañías extranjeras, por ejemplo, preferían a los creoles que hablaban inglés. Así, en los talleres y muelles, los mejores puestos los ocupaban éstos y los morenos y latinos realizaban los trabajos más rudos. ${ }^{17}$

La escritora Xiomara Mercedes Cacho Caballero (1968) es una de las más importantes autoras garífunas, que responde a los propósitos de esa tradición afrocéntrica que "se inscribe en los propósitos e intenciones de la estética negra". ${ }^{18}$

Nació en Punta Gorda, Roatán, Islas de la Bahía. Domina cuatro idiomas y tiene estudios de educación especial. Es la representante de la comunidad garífuna en el Programa Nacional de Educación Bilingüe Intercultural. Publicó La voz del corazón en 1998. Fue la primera mujer garífuna en publicar un libro de poesía en Honduras; de hecho, es la primera mujer negra que escribe poesía y cuento en ese país. La crítica Helen Umaña la incluye en la obra La palabra iluminada. El discurso poético en Honduras (2006) y señala que la autora ha vivido en un lugar donde confluyen tres culturas y que, por ello, el título y los poemas están escritos en garífuna, español e inglés. Afirma que "por primera vez en la historia de la poesía hondureña, una mujer de la etnia garífuna realiza un esfuerzo de integración intercultural". ${ }^{19}$ La crítica destaca como preocupaciones en la escritura un deseo de afirmar la cultura e identidad garífuna frente a un presente que tiende a desdibujarla. Asimismo rescata el orgullo por las raíces africanas y el sufrimiento y la crueldad de la llegada de sus antepasados a América. ${ }^{20}$

\footnotetext{
${ }^{16}$ Mark Anderson, "Los garífuna hondureños y los significados de 'negro' en los años 1930 y 1940", en Cunin, op. cit., p. 50.

${ }^{17}$ Ibid., p. 51.

18 Magda Zavala, "Poesía, género y etnia en Centroamérica", en Centroamericana 12, Milán, Universidad Católica del Sagrado Corazón, 2007, pp. 121-141.

${ }^{19}$ Helen Umaña, La palabra iluminada. El discurso poético en Honduras, Guatemala, Letra Negra, 2006, p. 739.

${ }^{20}$ Ibid., pp. 739 y 740.
} 
Otro grupo de poemas son hermosos cantos al amado en los que se expresa la sensación de plenitud cuando él está presente, o de nostalgia en el periodo de ausencia. Estos poemas seguramente están relacionados con el proceso de emigración de los varones. En general, en el libro no se encuentra un compromiso particular con la condición femenina o temáticas de género, con excepción del poema "Eres tú", que expresa la violencia sobre una mujer negra que tiene un hijo del patrón blanco, situación que es un riesgo en la ocupación como trabajadora doméstica y en esas creencias estereotipadas y erotizadas de la mujer negra.

El poemario Tumálali Nanígi/ La voz del Corazón/The voice of the heart es una colección de 24 poemas, ocho en cada uno de los idiomas en los que escribe su obra literaria: inglés, español y garífuna. Algunos, como "Sueño", se encuentran en los tres idiomas. El libro inicia con el poema "Garáwon" ("Tambor"), un poema que anuncia la motivación para escribir de la autora: ese deseo de afirmación de la cultura, la conservación en la memoria de sus raíces negras y el orgullo por las tradiciones que permite la supervivencia de la identidad étnica a través de las generaciones:

iLos niños de mi pueblo!

Conservan sus costumbres

Y hablan de dugú,

Muy felices,

Ofrendan comidas a sus ancestros,

Aman la comunidad nacional, también tocan el tambor.

Los niños de mi pueblo conservan su identidad cultural,

Labran la tierra, creen en el desarrollo,

iCómo tocan el tambor los niños de mi pueblo!

Conservan lo de sus ancestros,

Hablan de su identidad. ${ }^{21}$

${ }^{21}$ Xiomara M. Cacho Caballero, Tumálali Nanigi/La voz del Corazón/The voice of the heart, Tegucigalpa, edición de la autora, 1998. 
En otros poemas la pérdida de la identidad es expresada como lamento, con dolor, porque la historia, pasada y presente, ha destruido los rasgos de la memoria y la cultura garífuna. Los garífunas se encuentran rodeados de un discurso y un universo simbólico que los excluye, sin referentes particulares referidos a su etnia, de tal manera que para "pertenecer" tienen que dejar de lado su identidad: éste es el sentido del poema "Alarido":

\section{Coloquiales}

Sobre ese germen

De riqueza cultural

Esa historia prospectiva

¿Cuál es el pasado

De este presente que succiona

Dejando en interrogante la sobrevivencia

de la identidad?

$[\ldots] \cdot{ }^{22}$

En "Relying" expresa esa pérdida de valores de la etnia y la sustitución por otros valores de origen occidental. Se encuentran dentro del discurso pero desde una definición y mirada que no corresponde a los propios valores. Atrapados en sensaciones de enajenación o extrañamiento de sí mismos como producto de la relación subordinación y dominación que se deriva de su inserción en las economías de enclave, como marineros y fuerza de trabajo barata, y como producto de procesos migratorios que inician en las ciudades capitales hasta llegar a Estados Unidos. Es un poema de rebelión y resistencia a una cultura que continúa explotándolos:

$[\ldots]$

They are still dominating us

Contact with enclave work

Shipping out'as crew

Migrating to the towns

${ }^{22}$ Ibid., p. 18. 
Then to the USA

Relying on dollar remittances supplementing earnings

Putting values in our mind.

$[\ldots]{ }^{23}$

Esa enajenación producto de la inclusión/exclusión en el discurso se expresa en el poema "Tono", que muestra un ferviente deseo de "estar dentro", construir una identidad colectiva y esperanza en el futuro. Sin embargo, el segundo verso muestra la exclusión y no permite escapar a ese atrapamiento. Palabras como heroísmo, alianza, futuro, fe, opresión, aturdimiento, castración y nutritivo brindan el tono del poema:

Van de tono en tono,

Heroísmo de cristales que

Reflejan existencia en alianza;

El futuro convertido en fe.

Ausencia de toda impresión luminosa

Impresión análoga,

Opresión del fruto

Aturdimiento de las ramas y flores

Castración del tronco,

Pugnanza del sostén

De procedencia que absorbe lo nutritivo. ${ }^{24}$

Otros poemas, como "Scream", expresan la necesidad de no olvidar, mantener una memoria viva y construir un "nosotros" como identidad política. Es fundamental, por ello, la conservación de la lengua garífuna para pensarse a sí mismos, nombrar esos procesos de resistencia y de toma de conciencia frente a la explotación y a esa relación de opresor y oprimido, amo y esclavo:

23 Ibid., p. 11.

${ }^{24}$ Ibid., p. 9. 
$[\ldots]$

Each from different

Historical experience

We develop;

Master and interbred population

Heavy labour for unskilled black.

Seeking to replace

Your garifuna language

Where forbidden,

hostility, frustration, but

You are still there. ${ }^{25}$

El poema "Speak to us" es una oración profundamente transgresora, muestra ese sentimiento de pérdida, de oscuridad por el olvido de la lengua. Se dirige a un dios-padre para que guíe a sus hermanos, son los varones los que emigran, que no se dejen engañar por una educación que los obliga a olvidarse de su etnia, su lengua y su memoria:

Father; I know you are there

Talk to us

Look to us

Look at us now

We are getting lost

Do not let us be in darkness

Give us a hope of promises

Do not let education

Misplace my brother

My brother is not the same now

He does not speak his language anymore

Brush away, the misunderstanding of him. ${ }^{26}$

\footnotetext{
25 Ibid., p. 2.

${ }^{26}$ Ibid., p. 17.
} 
"Ancestros" da cuenta de las raíces africanas en la construcción de la memoria e identidad garífuna. Recupera el sufrimiento y la muerte durante el trayecto a América de los antepasados traídos como esclavos. El poema hermana a los garífunas con el resto de los afrodescendientes porque ellos no fueron esclavos, fueron negros cimarrones que se rebelaron, escaparon y llegaron a América sin el yugo de los amos:

¿Cuántos de ellos murieron?

El mar fue el único testigo

De aquellos que vinieron

A abrir el camino hacia la América.

Murieron muchos.

Otros llegaron a la América.

Cuántos cantos sobre ese movimiento;

Cuántos cantos por la sangre.

Cuánta desesperanza

Cuánta deshumanización, Fueron tantos,

Pero ninguno fue escuchado.

Cuántos de ellos murieron,

Todos murieron de dolor;

Muchos gritaron socorro,

Pero ninguno fue escuchado.

$[\ldots]$

iOh, Ancestros!

Dónde han quedado tus alaridos

Cuánta desesperanza,

Cuántos de ellos murieron. ${ }^{27}$

En ese mismo sentido de ubicarse en un movimiento político más amplio que incluye a todos los afrodescendientes en Centroamérica y rebasa, también, las fronteras de la región, el poema "Sueño"/"Dream" alude a Martin Luther King Jr., figura emblemática en el movimiento panafricano. En un sentido de afirma-

${ }^{27} \mathrm{Ibid}$., p. 12. 
ción expresa el amor, el orgullo y el dolor por sus antepasados africanos pero con la esperanza de construir ese sueño, esa utopía en la que sea posible ejercer la ciudadanía sin que el color de la piel represente discriminación. La escritora incorpora un elemento adicional: la reafirmación de una conciencia negra universal.

\author{
¿Has visto un sueño avanzar? \\ Pues yo sí lo vi \\ ¿Has visto lo bien que tu sueño puede avanzar? \\ Es divino y maravilloso. \\ El sueño avanza \\ Cuando el cielo llega a tus brazos. \\ ¿Has visto lo bello que avanza tu sueño? \\ Pues yo sí lo vi. \\ El cielo en tus brazos \\ Es la conciencia del color de tu piel \\ Ante los ojos de la sociedad \\ Es la frescura de tu pigmentación. \\ Lo maravilloso es \\ La sangre africana. \\ Es el dolor que sufrieron \\ Aquellos que te abrieron \\ Las puertas a la América. ${ }^{28}$
}

Have you ever seen a Dream advance,

Well I did see it,

Have you seen how well dream can go

forward?

It is divine and marvellous.

Then dream progresses

When the sky reaches your arms.

Have you seen how beautifully your

dream advances?

Well I did see it.

${ }^{28}$ Ibid., p. 6. 
The sky in your arms

Is the conscience of the colour

of your skin

Before the eyes of society.

And the freshness of your pigmentation.

What is marvellous is

The African Blood.

The pain that was suffered

By those who opened to you the doors of

the Americas. ${ }^{29}$

\section{ISABEL ESTRADA COLINDRES: NicARAGUA}

El caso de Nicaragua es muy particular. En el periodo posterior a la Revolución, se establece un régimen de Autonomía de las dos regiones de la Costa Atlántica de Nicaragua: la Región Autónoma del Atlántico Norte (RAAN) y la Región Autónoma del Atlántico Sur (RAAS). La Costa Caribe ocupa un poco más del territorio nacional y fue "colonizada por los ingleses y a diferencia del Pacífico, donde los pueblos indígenas sucumbieron al mestizaje, en esta zona aun existen pueblos indígenas autóctonos y afrodescendientes, con su lengua materna y cultura", lo que genera una gran diversidad étnica, lingüística y cultural. ${ }^{30}$ En el territorio conviven pueblos indígenas y comunidades étnicas, como los ramas, sumo-mayangna, miskitos, creoles, garífunas y mestizos. Esta diversidad de pueblos y comunidades se identifican como "costeños" y en esa utopía común de la Autonomía encuentran el espacio para reconocer semejanzas y diferencias, y encontrar un lugar libre de discriminación, racismo, expropiación y exclusión. ${ }^{31}$

29 Ibid., p. 5.

30 Yolanda Rossman Tejada, Una aproximación a la autonomía multicultural desde la poesía de escritoras costeñas, Bilwi, 2006 (Tesis de maestría en Antropología Social con mención en Desarrollo Humano, Universidad de las Regiones Autónomas de la Costa Caribe Nicaragüense).

31 Yolanda Rossman, "Aquí la palabra es arcoiris", en ANIDE, año 5, núm. 12, Managua, mayo-agosto de 2006, p. 54. 
Las poetas costeñas afirman que la Autonomía representa su utopía de mujeres comprometidas con su realidad sociocultural. ${ }^{32}$ Yolanda Rossman señala la existencia de 28 mujeres poetas, lo que muestra que esa tradición literaria está siendo consolidada por mujeres. La identidad cultural, ritos, tradiciones, costumbres, género, autonomía, conciencia social y el respeto por los recursos naturales son temas recurrentes en sus poemas. ${ }^{33}$

Entre este grupo de poetas se encuentra Isabel Estrada Colindres (1953), garífuna nacida en La Fe, Cuenca de Laguna de Perlas, Bluefields/RAas. Es enfermera y socióloga, responsable de la Promotoría en la Asociación Campaña Costeña de Lucha contra el SIDA e integrante del Programa de Revitalización de la Cultura Garífuna. Escribe en inglés, creole y español diferentes poemas sin traducción. Se incluye un poema de su autoría en la Antología Poética de la Costa Caribe de Nicaragua y en el libro Orinoco: revitalización cultural del pueblo garífuna de la Costa Caribe nicaragüense (1999).

$\mathrm{Al}$ igual que Xiomara Cacho, Miss Isabel (como se le conoce en Bluefields) expresa, en el poema "Yesterday", la preocupación y el dolor entre los garífunas por la fuerza con que fueron absorbidos por la cultura creole que ha llevado a la pérdida de su lengua y buena parte de su cultura. ${ }^{34}$ En este sentido, los garífunas se encuentran en una relación de marginalidad adicional como grupo minoritario entre los afrodescendientes, que a su vez representan una minoría respecto a la cultura de origen hispano. El poema recupera los sabores de sus comidas tradicionales, el pescado, el coco, el plátano y el pan de yuca. Asimismo, los rasgos de su cara y de su cuerpo, las voces de los ancestros que se escuchan a través del tiempo, el sonido de los tambores de sus antepasados africanos y los pies que siguen el ritmo curativo de los sonidos. Es un poema pleno de sen-

${ }^{32}$ Hasta el presente se han publicado dos antologías que recuperan la tradición oral (leyendas, mitos, canciones, juegos, danzas) de la costa Caribe: Miskito Tabaza (Tierra Miskita) de 1998 que recoge prosa y poesía de escritores, escritoras y poetas de la Región Autónoma del Atlántico Norte (RAAN) y Antología Poética de la Costa Caribe de Nicaragua (1998) de poetas de la Region Autónoma del Atlántico Sur (RAAS). Véase Rossman, Una aproximación a la autonomía..., pp. 26 y 27.

33 Ibid., pp. 54-58.

${ }^{34}$ Ibid., p. 56. 
sualidad que expresa la capacidad del cuerpo y sus sensaciones para vaciar los símbolos de los significados que los alejan de su memoria, y llenarlos de nuevos sentidos lúdicos que emanan del orgullo y la fortaleza de la etnia. Rompe así con la enajenación:

Yesterday, today, tomorrow, forever

Our voice will shout all over

When I horde the word Garifuna, I thought

About yesterday kereb, I thought yesterday kumpe

I thought yesterday Driff coconut,

I thought cat fish eater.

Yesterday, today, tomorrow, forever our voice is out.

Garifuna the round ushnu on our back

Sweet and biter cassava, delicious bami

Plantin dashin, nice judut.

Garifuna tick lips

Garifuna big flat nose

Garifuna big rollin buttock.

When I horde sound of my father drum

Drum, drum, drum

The sound of my grandfather drum

Drum, drum, drum

My feet keep moving on mother ground

For the healing of our ancestors walagallo.

Garifuna, garifuna, garifuna

Yesterday, today, forever

Our voice will shout all over. ${ }^{35}$

La figura de las abuelas es importante no solamente porque en ellas radica la transmisión de la memoria y la cultura, sino también porque frecuentemente ellas quedan a cargo de las nietas y nietos cuando la generación intermedia debe

35 Yolanda Rossman Tejada, Aquí la palabra es arcoiris. Poemario de Mujeres de la Costa Caribe de Nicaragua, 2010, p. 8 (inédito). 
emigrar en la búsqueda de mejores oportunidades para el sustento familiar. Son ellas las que cuidan, alimentan, educan y enseñan las tradiciones religiosas y de la etnia a los nietos. La abuela del poema "Grani", escrito en creole, proporciona calor, alegría y un sentido de fiesta en la vida cotidiana de los nietos, fortaleciendo con ello su autoestima e identidad:

Such a sweet an wondaful wod

But I moo sweta when yu get ina the club.

Some a we newa eva sing But wen we gran baby get Ina we han all cain a song Com up to we hed fu sing Ja, ja a tel yu buai!

Some a di grani dem so kain An waam but some ai mi deer Di original grani de no dem We gi yu wan dal baby, wan Bal, nida wan dras da Christmas time Nida dem we want dem granpicknini Line all ova to dem moo an dem Muma. No mi dere di real grani da hou Help fu bring up dem gran baby Wid respect, love, an a licu bit A all the life substan so dem cud Fit to place ina dis ya wol Now yu no huo da di real grani? ${ }^{36}$

La tía-abuela de la poeta, como pasatiempo, anotaba en una serie de cuadernos todos los acontecimientos de la vida cotidiana de la comunidad de Santa Fe. Ella sabía cómo había sucedido y quiénes habían participado en cualquier suceso del que se hablara. Llevaba, sin pretenderlo, la historia de la comunidad y

${ }^{36}$ Loc. cit. 
el registro de las tradiciones de sus habitantes garífunas.$^{37}$ Es posible que esta apropiación de la escritura y la palabra haya sido heredada a la poeta por esa vía, una expresión de la matrilinealidad de la cultura garífuna.

La investigadora Yolanda Rossman presenció una reunión de mujeres garífunas en Santa Fe, Bluefields, Nicaragua, donde se expresó como una de las grandes inquietudes, el avance de la frontera agrícola por parte de la población mestiza y miskita, de tal manera que, en son de broma, una de las participantes apuntó "la necesidad de dedicarse a procrear sin descanso para que la comunidad crezca y los territorios deshabitados sean ocupados por garífunas. ${ }^{\prime 38} \mathrm{La}$ investigadora señala que las participantes eran mujeres de distintas generaciones preocupadas por el bienestar de su pueblo y que se comunicaban entre sí intercalando el inglés y el español. ${ }^{39}$

El compromiso de Miss Isabel se muestra en la preocupación por la depredación de las comunidades que ocupan los garífunas por parte de la explotación irresponsable de los recursos que realizan las empresas asentadas en la región. El poema "La Fe" se refiere al lugar donde nació, esa tierra donde se encuentra enterrado su cordón umbilical y a la que pretende regresar:

iLa Fe! La tierra prometida de mi cordón umbilical.

La tierra de mis pasos vacilantes

La tierra de mi primera palabra.

iLa Fe! ¿Cómo podría olvidarte?

¿Cómo podría alejarme de ti?

Si tú me enseñaste a gatear

A caminar, a correr y a jugar.

iLa Fe! El problema por el que ahora sufres

Es que las aguas te están arrastrando

iTerraplén Maravilloso!

iQue triste es ver que te vas

37 Rossman, Una aproximación a la autonomía..., p. 55.

${ }^{38}$ Ibid., p. 57.

${ }^{39}$ Loc. cit. 
Debemos hacer algo!

iTenemos que hacer algo! $!^{40}$

\section{Lecian Haye Francis y Nora Murillo: Guatemala}

En la costa atlántica de Guatemala, Livingston y Puerto Barrios, radica un grupo de garífunas que no llegan a ocho mil habitantes, representan un grupo minoritario que vive con pocas oportunidades de trabajo y desarrollo integral y poco acceso a la educación, salud y vivienda. ${ }^{41}$ Es raro encontrarse con garífunas fuera de esta región perteneciente al departamento de Izabal. El racismo y la discriminación dificultan su integración en el resto del país. En la actualidad hay un proceso de asimilación de los jóvenes a la sociedad guatemalteca, lo que tiene como consecuencia el abandono de su herencia cultural para ser aceptados en la sociedad más amplia. ${ }^{42}$

La antología de poetas guatemaltecas Transitando entre la subjetividad poética y la comunicación (2008), compilada por la investigadora Rossana Estrada, recupera a dos poetas garífunas: Lecian Haye Francis y Nora Murillo. Lecian Haye es originaria de Livingston, Izabal, y nació el 5 de agosto de 1962. Es estudiante de la Universidad Rafael Landívar y su obra permanece inédita. Su poesía tiene como sujeto a las mujeres de su etnia en la que a menudo hace alusión a los rasgos físicos de la mujer garífuna y al color ébano de la piel. No es una poesía feminista en un sentido político pero sí le permite a sí misma y a sus lectoras pensarse como mujeres de piel oscura, pobres y discriminadas, que se resisten a ser invisibilizadas por la cultura ladina:

Sonría dulce de coco.

Cabellos de búfalo

${ }^{40}$ Ibid., pp. 90 y 91. Poema traducido al español por Ronald Brooks.

${ }^{41}$ Rossana Estrada Buccaro, Transitando entre la subjetividad poética y la comunicación, Guatemala, Universidad de San Carlos de Guatemala, 2008, p. 255.

42 Véase el blog garífuna que administran Benjamin Palacios y Yasmine Ernst. En http://garifunafiles.wordpress.com. 
Piel de ébano

Labios de mujer

Muñeca barbie de mi pueblo,

zapatitos de pies descalzos. ${ }^{43}$

Para ello, brinda a las mujeres un nuevo imaginario que recupera sonidos, como el tambor, que aluden al pasado y ritos africanos y al valor y fortaleza de generaciones de mujeres garífunas que han resistido:

Como un ébano

bañada en sudor

es la mujer de mi pueblo.

Que camina, lucha, llora y sonríe.

Levantada al canto del tambor

Buscando el Mazapán... ${ }^{44}$

Otras imágenes que presenta son el mar y ese trayecto de sufrimiento producto de las múltiples migraciones, ese éxodo en la búsqueda de un lugar que reconozcan como su hogar. En este proceso de construir una memoria y una identidad recupera la ternura y fortaleza de las mujeres:

Pensamientos

proyectos tiernos de mujer

cruzando el mar y descubriendo un cielo café

la identidad... Soy mujer y puedo.

La mujer es el grito de la vida,

el ocaso en el infinito

Dolor hiriente continuo.

¿Quién ha conocido su llanto?

¿Dónde están los que ya se fueron?

dolor dime ¿Qué es?

${ }^{43}$ Estrada, op. cit., p. 249.

${ }^{44}$ Ibid. 
Oscuridad y abandono en el duro andar de la vida.

Luz quizás, no lo sé.

Solamente mujer, capaz y fuerte... Mujer. ${ }^{45}$

La obra de Lecian Haye muestra una conciencia de su identidad en dos sentidos: como afrodescendiente y como mujer. Mujeres creadoras de identidad e historia, mujeres que expresan la capacidad del amor con la misma fuerza de un huracán, es éste otra de las figuras emblemáticas presentes en el imaginario caribeño:

Una mujer, es una estrella en el infinito.

Es dolor, sin miedo.

Es amor, sin espera.

Creación sublime de Dios

grito de la naturaleza en la aurora.

Silencio en el atardecer

huracán en el amor. ${ }^{46}$

Finalmente la poeta expresa su reconocimiento a las mujeres ancianas y a su importante labor como forjadoras de la memoria y transmisoras de la cultura y la identidad de su pueblo, y de las mujeres de la etnia:

Vestidos gastados por el tiempo, mirada hundida y penetrante sonrisa que a través del tiempo se hizo tu luz.

45 Ibid., p. 250 .
46 Ibid., p. 49. 
Mujer anciana que por mi pueblo andas eres mi paso y un poquito a la eternidad.

En ti, veo ese escondite de fuerza.

Quédate a mi lado siempre... y en el más allá. ${ }^{47}$

Nora Murillo nació en Livingston en 1964, es trabajadora social e investigadora y docente universitaria. Fue parte del colectivo literario El Quinto Infierno. Sus textos han sido publicados en las revistas Noticias de Guatemala, El Nuevo Milenio es Nuestro, Verdad y Vida, Nunca más, Los que escriben y Amiga; en los periódicos y suplementos Siglo XXI, La Cuerda, El Periódico, Co-Latino (San Salvador). Ha ganado varios premios literarios, entre ellos el Premio de Poesía Alaíde Foppa en el año 2000. Publicó el poemario Abrir la puerta. ${ }^{48}$ En él se puede observar a un sujeto femenino que se dirige a las mujeres. "Maíta" recupera a las ancestras en esos movimientos migratorios y su lucha de resistencia a la esclavitud, a la par de los varones. También esa luz y sabiduría que es la guía en la vida cotidiana y permite la sobrevivencia de la cultura. Las imágenes aluden al mar, las palmeras y los huracanes: a su pasado y presente.

\author{
Su risa \\ una mueca \\ dibujada por los años \\ Su cabello \\ sombra ceniza frente al mar \\ Su cuerpo \\ una palmera \\ resistiendo huracanes \\ Toda ella \\ un faro \\ arriba de la casa
}

${ }^{47}$ Ibid., p. 250.

${ }^{48}$ Ibid., p. 251. 
Luz

que silenciosamente

marca huella. ${ }^{49}$

En Nora Murillo se encuentra, además, una propuesta feminista respecto a la concepción de mujer que niega la pasividad y la dependencia emocional respecto al varón, pero que no implica el rompimiento. El poema "Mujer" no hace relación a su identidad étnica, muestra una búsqueda de la identidad femenina autónoma sin sacrificar la relación amorosa:
Como trompo
rompes ataduras
dejas de ser puente
derribas obstáculos
emprendes caminos
hasta llegar a ser
Saberte amada
amar...
sin miedo a descubrir
que a veces te tropezás
Pero eres cada vez: más libre

$$
\begin{aligned}
& \text { más hermosa } \\
& \text { más valiente } \\
& \text { más Mujer. }{ }^{50}
\end{aligned}
$$

En el poema "Abrir la puerta" se observan ya figuras que aluden a ese trayecto del pasado africano, los rituales y el trayecto por el mar de los esclavos: el reflejo de la luna, la niebla, las máscaras y las cadenas. Imágenes que se enlazan con nuevos ritos como mujer autónoma en el presente que afirman esa búsqueda de la identidad femenina, trastocando y subvirtiendo los valores aprehendidos, rebelándose a las enseñanzas de las abuelas, al dolor y al silencio.

\footnotetext{
49 Ibid., p. 252.

${ }^{50}$ Ibid., p. 253.
} 
No busqué la llave

en un bolsillo roto

en un zapato viejo

Busqué en mis ojos

las siete lunas

despiertas en la niebla

Me sacudí con fuerza

hasta botar el moho de silencio

Abrí el armario

apolillado

el que me regaló la abuela

para guardar mis lágrimas

Tiré cosas viejas

Ideas, mandamientos, cadenas...

Me quité las máscaras

me vi

Apreté los puños

rompí ventanas

Abrí la puerta

y me tomé la calle. ${ }^{51}$

Su poesía presenta el conflicto con "el otro", el varón, probablemente como un reclamo a las frecuentes ausencias producto de procesos migratorios, o por los desencuentros derivados de las identidades de género en las sociedades patriarcales.

"Jaque Mate"

Te perdiste en mi sueño

en mi encierro

51 Ibid., p. 254. 


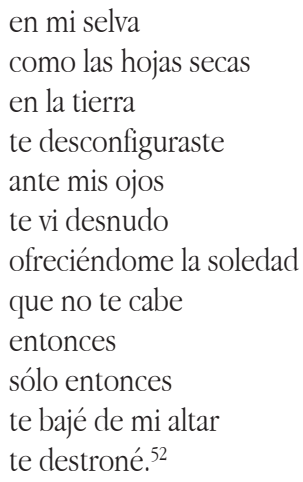

La poeta describe en el poema "Mutación", el conflicto que surge del enfrentamiento con la cultura patriarcal. Expresa el valor de las mujeres y su energía para nadar contracorriente, un movimiento de las mujeres para las mujeres en el que cada una, a su propio ritmo, transita y construye el camino a recorrer para las otras:

Cuando nos han dicho siempre

lo que debemos y no debemos hacer,

cuando nos han condenado a sobrevivir alejadas de nosotras mismas,

elegir lo contrario a lo impuesto es difícil y subversivo.

Significa aprender a caminar al revés y ponernos en el centro de la mirilla...

Lo cierto es que somos miles de mujeres mutando.

Cada una a su manera, con su propio reloj, en diversos espacios.

Somos mujeres haciendo camino

para transformar esta cultura patriarcal que nos oprime..$^{53}$

52 Rossana Estrada Buccaro y Romeo Moguel Estrada, Voces de posguerra. Antología de poesía guatemalteca, Guatemala, Fundación Guatemalteca para el Desarrollo del Arte, 2002, p. 188.

53 Cartel de Colectiva de Mujeres en las Artes de Guatemala. 
En este mismo sentido, el poema "Confieso que esperé..." es una voz beligerante que reclama los derechos de las mujeres, que manifiesta las diferentes expresiones de violencia a las que las mujeres - sin importar clase, raza o etniason expuestas; la historia de sometimiento y las instituciones sociales que legitiman y reproducen esa subordinación y ausencia de poder. En esa rebeldía alude a una historia matrilineal de mujeres transgresoras que han alumbrado y acompañado el camino para otras mujeres. El poema tiene como objetivo la lucha por la plena humanidad de las mujeres, similar a la lucha de esos negros cimarrones que se negaron a la esclavitud. Como subtexto se encuentran imágenes que hacen referencia a esa historia: las tormentas, los barcos, las barcas a la deriva, la luna, los puertos. Finalmente muestra un deseo de reconciliación entre la historia personal y la historia de Guatemala, que, como los discursos androcéntricos, es una historia escrita desde un contexto objetivo que recoge las experiencias de los varones y una ideología que coloca en los márgenes a las mujeres y las etnias.

Esperé que pasaran las tormentas

Que se descongelara la noche

Que en mi puerto no atracara un solo barco

Que los duendes me regresaran las palabras

Esperé como miles de mujeres:

En el anonimato...

Aguantando la triple jornada,

el medio salario

el jefe abusivo

el último puesto...

Conviviendo con el enemigo en casa, la iglesia, la escuela, la calle...

Esperé con el corazón y arrugado de miedo

Con tristeza y angustia contenidas

Con rabia e impotencia de sentirme barca a la deriva

Esperé...

rastreando las huellas y convocando la voz

de hermanas que escriben sus nombres con mayúscula 
ESPERANZAGUADALUPEREINAFRANCISCAMARIAJUANA

MARTAISABELAMANDAIXMUCANECELIADOMINGALAURA...

Obreras, campesinas, estudiantes, profesionales, madres,

trabajadoras, artistas, indígenas, mestizas,

luchadoras, rebeldes, insumisas...

Mujeres que se cansaron de que todo les llegara tarde.

Esperé

hasta sentir que ya no podía esperar más

Porque mi corazón hervía de emociones

Porque mi piel fue absorbiendo un viento nuevo

Un viento que me hacía girar...

Y... giré..., giré... giré... giré... giré...

hasta sentirme reencontrada con mi historia

y la historia de este país que habito y me habita

Desde entonces ya no "sueño con serpientes"

Sueño con lunas cargadas de caramelos

Con dragones que me abrazan

Con árboles que caminan...

Y aquí me tienen...

Soy una más, ique no calla! $!^{54}$

\section{CONCLUSIÓN}

Las poetas garífunas son mujeres nacidas en la década de los sesenta, con excepción de Isabel Estrada Colindres, de Nicaragua, nacida en 1953. Ordenadas por año de nacimiento le siguen las guatemaltecas Lecian Haye Francis, nacida en 1962 y Nora Murillo, en 1964. La más joven es la hondureña Xiomara Cacho Caballero, nacida en 1968. Su escritura se encuentra inserta en los movimientos sociales que surgen a partir de la década de los sesenta.

Su obra ha sido recuperada en antologías y solamente Xiomara Cacho ha publicado un libro de edición propia, lo que tampoco es raro en la publicación de libros de escritoras centroamericanas. Isabel y Xiomara son activistas políticas

${ }^{54}$ Ibid. 
que luchan por los derechos humanos de los integrantes de la etnia. Xiomara escribe ensayo en este sentido.

Respecto a las temáticas, se encuentra una reivindicación de la memoria simbólica africana. En Xiomara Cacho, las imágenes se refieren a sus ritos y tradiciones, los sonidos del tambor de los antepasados. Incluso, algunos de sus poemas tienen ese ritmo, otros aluden al mar y al trayecto de África a América en los barcos esclavistas. Escribe en garífuna, inglés y español. Cabe destacar que es la única que escribe en lengua garífuna. Isabel Estrada Colindres igualmente recupera el sonido de los tambores, su magia curativa, su ritmo en la poesía y sus tradiciones y ritos. Escribe en inglés y creole. Llama la atención que esta poeta que expresa con mayor dolor el olvido de la lengua y la cultura, no escriba en lengua garífuna. Lecian Haye utiliza también la imagen del tambor, del mar y los huracanes. Nora Murillo presenta en su poesía feminista imágenes referidas a las tormentas, los barcos, las barcas, los puertos y la luna. Ambas autoras escriben en español.

Las autoras escriben desde una perspectiva interior, asumiéndose como una voz más de los miembros de su etnia que expresa sus preocupaciones y procesos de marginación, subordinación y explotación. La poesía como discurso, adquiere sentido en esa búsqueda de la identidad como integrantes de la etnia garífuna, como afrodescendientes, y como mujeres. Cabe aclarar que las escritoras guatemaltecas no hacen referencia particular a su etnia pero en las imágenes reconocen su pasado africano. Las cuatro autoras expresan con orgullo los rasgos físicos de su etnia y el tono de la piel. Solamente Xiomara Cacho Caballero recupera imágenes y personajes que la unen al movimiento panafricano, como el famoso discurso "Tuve un sueño" de Martin Luther King Jr.

Xiomara e Isabel, como se señaló, son activistas políticas que luchan por el reconocimiento de los derechos de los garífunas, realizan acciones para la recuperación de las tradiciones y de una lengua garífuna que les permita pensarse, nombrarse y construir su memoria y su historia. Asimismo, Xiomara muestra esa enajenación de la conciencia garífuna por el contacto con sociedades que funcionan como economías de enclave. Isabel expresa la depredación de las comunidades garífunas que estas economías realizan. En la producción ensayística, Xiomara 
Cacho señala la urgencia de una educación que tome en cuenta el carácter pluriétnico y plurilingüístico de Honduras, la educación regular no les brinda los conocimientos para resolver los problemas sociales relacionados con la supervivencia y calidad de vida de las etnias. Es una educación en español, los textos escolares, las metodologías y los recursos pedagógicos reflejan la cultura de origen occidental, desconociendo otras lenguas, culturas, demandas y necesidades. ${ }^{55}$

Lo señalado por la autora es aplicable al resto de los países. En este sentido esa enajenación y fragmentación de la conciencia sólo puede ser superada con la apropiación de una lengua, un imaginario cultural y procesos educativos que les brinden los bienes simbólicos y materiales para construir su identidad en un sentido político. Requieren para ello vaciar los símbolos culturales dominantes de esos significados que los incluyen en condiciones de otredad, marginalidad y explotación para resignificarlos y llenarlos de nuevos contenidos que les permitan construirse como ciudadanos y ciudadanas en los diferentes países en los que viven. Este discurso es la salida que las poetas proponen a esa inclusión/exclusión en el discurso hegemónico respecto a la etnia garífuna, presentes e invisibles a la vez en la construcción y desarrollo de sus países y de la misma manera, las mujeres discriminadas por su condición étnica y de género en las sociedades patriarcales.

La escritura de Xiomara no es sexuada, pero en Isabel ya se encuentran referencias a la importancia de las abuelas en las comunidades garífunas; son ellas las que quedan como responsables de la transmisión de la cultura de los menores en un sentido amplio: los valores, las tradiciones, los ritos y la división sexual y social del trabajo. La escritura de Lecian tiene como sujeto a las mujeres garífunas; las describe físicamente, recupera su fortaleza como mujeres creadoras de identidad e historia y reconoce a las ancianas en su papel de transmisoras de la cultura. En Nora se encuentra una propuesta feminista que va más allá de la etnia. Hace referencia a la búsqueda de la identidad femenina que subvierte los

55 Xiomara Mercedes Cacho Caballero, "Derechos económicos, sociales y culturales de la población garífuna isleña en Honduras", en Revista 7, Corte Interamericana de Derechos Humanos. En www.corteidh.or.cr/tablas/R23006.pdf. 
símbolos que las instituciones patriarcales construyen para privarlas del deseo de protagonizar la propia historia y la historia de las sociedades. La matrilinealidad la expresa no por los lazos de sangre, sino recuperando a aquellas mujeres "obreras, campesinas, estudiantes, profesionales, madres, trabajadoras, artistas, indígenas, mestizas, luchadoras, rebeldes, insumisas" que hermanadas en la lucha han abierto el camino para otras mujeres que, igualmente, se han cansado "de que todo les llegara tarde".

En los textos recuperados no se observa el ejercicio del poder y la autonomía de las mujeres que se esperaría en una cultura matrilocal y matrilineal. Sin duda se debe a que es un poder limitado que no incluye el poder económico y que reproduce la dependencia respecto a los varones. En Xiomara Cacho Caballero, Isabel Estrada Colindres y Lecian Haye Francis, el discurso poético muestra ese temor y resistencia a ser absorbidos por la cultura "ladina" (mestiza). Nora Murillo, además, expresa la resistencia a la subordinación femenina en las sociedades patriarcales. En Xiomara y Nora, las más jóvenes, se encuentra una propuesta de utopía, afroamericana en la primera y feminista en la última.

Recibido: 18 de abril, 2012. Aceptado: 12 de junio, 2012.

BibLIOGRAFÍA

ANDERSOn, MarK, "Los garífuna hondureños y los significados de 'negro' en los años 1930 y 1940", en Elizabeth Cunin [coord.], Mestizaje, diferencia y nación. Lo "negro" en América Central y el Caribe, México, INAH, 2010, pp. 35-67.

Cacho Caballero, Xiomara M., Tumálali Nanígi/La voz del Corazón/The voice of the heart, Tegucigalpa, edición de la autora, 1998. 
Duncan, Quince. "El Afrorrealismo. Una dimensión nueva de la literatura latinoamericana", en Istmo. Revista Virtual de Estudios Literarios y Culturales Centroamericanos, núm. 10, enero-junio de 2005. En http://collaborations.denison.edu/istmo/n10/articulos/afrorealismo.html (fecha de consulta: 8 de octubre, 2009).

Estrada Buccaro, Rossana, Transitando entre la subjetividad poética y la comunicación, Guatemala, Universidad de San Carlos de Guatemala, 2008.

estrada Buccaro, Rossana y Romeo Moguel Estrada, Voces de posguerra. Antología de poesía guatemalteca, Guatemala, Fundación Guatemalteca para el Desarrollo del Arte, 2002.

IZARD, GABRIEL, "Garífuna y seminole negros: mestizajes afroindígenas en Centro y Norteamérica", en Elizabeth Cunin [coord.], Mestizaje, diferencia y nación. Lo "negro" en América Central y el Caribe, México, INAH, 2010, pp. 197-222.

López García, Víctor Virgilio, El papel de la mujer en la cultura garífuna, San Pedro Sula, Impresos Rápidos Ariel, 2007.

Rossman Tejeda, Yolanda. "Aquí la palabra es arcoiris", en Revista ANIDE, año 5, núm. 12, Managua, mayo-agosto de 2006, pp. 54-58.

\section{,Una aproximación a la autonomía multicultural desde} la poesía de escritoras costeñas, Bilwi, 2006 (Tesis de maestría en Antropología Social con mención en Desarrollo Humano, Universidad de las Regiones Autónomas de la Costa Caribe Nicaragüense).

, Aquí la palabra es arcoiris. Poemario de Mujeres de la Costa Caribe de Nicaragua, 2010, inédito.

UmaÑa, Helen, La palabra iluminada. El discurso poético en Honduras, Guatemala, Letra Negra, 2006.

Zavala, Magda, "Poesía, género y etnia en Centroamérica", en Centroamericana 12, Milán, Universidad Católica del Sagrado Corazón, 2007, pp. 121-141. 